\title{
An updated and extended earthquake catalogue for Greece and adjacent areas since 1900
}

\author{
K. Makropoulos, G. Kaviris, and V. Kouskouna \\ Department of Geophysics, University of Athens, Athens 15784, Greece \\ Correspondence to: K. Makropoulos (kmacrop@geol.uoa.gr)
}

Received: 5 March 2012 - Accepted: 20 April 2012 - Published: 11 May 2012

\begin{abstract}
A homogeneous earthquake catalogue for Greece and adjacent areas covering the period 1900-2009 is presented, to be used for reliable seismic hazard studies. The catalogues of Makropoulos and Burton (1981) and Makropoulos et al. (1989), covering the time span 1900-1985, were updated for the period 1986-2009 using instrumentally determined focal coordinates, except for the magnitude from the bulletin of the ISC. For $M_{\mathrm{s}}$, which is the magnitude scale included in the previous versions, the same procedure applied since 1964 was adopted, using the ISC body wave magnitude $\left(m_{\mathrm{b}}\right)$ and a regression equation. In the present update, $M_{\mathrm{W}}$ is also calculated for the entire period 1900-2009 using a formula derived from all available moment magnitudes and directly determined by the moment tensor inversion method. Thus, a magnitude homogeneous catalogue concerning both $M_{\mathrm{S}}$ and $M_{\mathrm{W}}$ scales is presented. The extended catalogue contains 7352 events, $70 \%$ more than the 4310 events of the previous published (1989) version. The completeness test revealed that the catalogue is complete for magnitudes above 4 for the last $34 \mathrm{yr}$ and that no earthquake with magnitude 6 or greater has been omitted in the whole instrumental era (1900-2009).
\end{abstract}

\section{Introduction}

Greece is located at the front of the collision between two tectonic plates, the Eurasian and the African, the front part of which is sinking under the former, as being a remnant oceanic crust, at a rate that exceeds $3-4 \mathrm{~cm}$ per year (Kahle and Mueler, 1998) SE of Crete. Apart from the collision front and due to its relatively small size, the area is considerably fragmented, consisting of numerous seismic zones. Half the energy of all the earthquakes occurring in Europe is released within the Greek territory. There is no province in the country that does not host seismic sources throughout the past centuries. Nevertheless, approximately $75 \%$ of Greek earthquakes occur either under the sea away from inhabited areas or at several kilometers depth, resulting in a reduced seismic risk. Thus, an earthquake catalogue which is as accurate, homogeneous and complete as possible will be very useful for a more comprehensive assessment of seismic risk in the region.

Many Greek earthquake catalogues have been presented since the late 19th century (Schmidt, 1879; Galanopoulos, 1953; Annales de l'Observatoire National d'Athènes 1893-1936; monthly and annual bulletins since 1950), but the first most systematic attempt to accumulate and classify all earthquakes over a certain magnitude $(\sim 5)$ was made by Galanopoulos (1960) for the period 1801-1958. Kárnik (1969) made an effort to present an earthquake catalogue for Europe for the period 1901-1955. In 1970 the UNDP/UNESCO Survey of the Seismicity of the Balkan Region compiled an earthquake catalogue (Shebalin et al. 1974a) which covers the period 1901-1970. The first attempt to relocate epicentres computed by the ISS for the Marmara region in north-west Turkey, which is included in the area of investigation of the present study, was performed by Crampin and Ucer (1975). Alsan et al. (1975) published the first computerized earthquake catalogue for Turkey and adjacent areas. Recent efforts for Greek earthquake catalogues are those by Burton et al. (2004) and by Papazachos et al. (2009).

The first earthquake catalogue for Greece containing recalculated source parameters including magnitudes according to a consistent scheme for the period 1900-1978 was published by Makropoulos (1978) and by Makropoulos and Burton (1981). The next version of the catalogue was further elaborated by Makropoulos et al. (1989), covering the 
period 1900-1985. Since then, a continuous effort has been made towards completeness and accuracy of the focal parameters estimation. For that purpose, the present catalogue was extended by incorporating earthquakes for the period 19862009. Furthermore, the calculation of the moment magnitude for the whole instrumental period (1900-2009), which is considered as the most reliable magnitude scale, was the second main scope of the present study.

\section{Hypocentral parameters}

Although data sources for hypocentral determination are described in detail in Makropoulos and Burton (1981), a brief summary of the procedure is provided in the current section. Thus, first phase arrival readings regarding the period 19131917 have been extracted from the monthly bulletins of the British Association for the Advancement of Science, whilst for the years 1918-1963, they originate from the bulletins of the International Seismological Summary (ISS). Hypocentral information since 1964 has been retrieved from the bulletins of the International Seismological Center (ISC), whereas additional information has mainly been extracted from the annual bulletins of the Seismological Institute at Uppsala (SIU) for readings at Uppsala (UPP) and Kiruna (KIR), as well as from the Unesco (UNS) (Shebalin et al., 1974a) and the Papazachos and Comninakis (1982) (PC) catalogues.

The area of investigation is identical to that of the previous versions of the catalogue (Makropoulos and Burton, 1981; Makropoulos et al., 1989), i.e. limited to latitudes $33^{\circ} \mathrm{N}$ to $42.5^{\circ} \mathrm{N}$ and longitudes $19^{\circ} \mathrm{E}$ to $29^{\circ} \mathrm{E}$ north of the $38^{\circ} \mathrm{N}$ parallel and to $30^{\circ} \mathrm{E}$ south of it, in order to include the area of the Dodecanese Islands.

For the period 1917-1963, earthquakes with available first arrival readings were relocated using the Joint Epicenter Determination (JED) method (Douglas, 1967) and Herrin68 travel-time tables (Herrin et al., 1968). As a result, 605 events were relocated, while the parameters (except for magnitude) of the remaining events were adopted from the UNS, PC, UPP, Galanopoulos (1960) (GAL), Alsan et al. (1975) (ATB) and ISC catalogues.

Concerning the period added in the present study, all parameters, except for magnitude, are those reported by the ISC (2010).

\section{Surface wave magnitude $M_{\mathrm{s}}$}

The surface wave magnitude $M_{\mathrm{S}}$ remains a useful tool for seismic hazard assessment, since seismic attenuation laws are usually expressed in terms of this magnitude scale. The $M_{\mathrm{s}}$ determination procedure is described in detail in Makropoulos (1978) and Makropoulos and Burton (1981). It is worth noting that, concerning earthquakes within the period 1900-1963, the main criterion for including them in the catalogue was that the event should have been registered by the Uppsala (UPP) and/or Kiruna (KIR) stations, with reported ground amplitudes.

The surface wave magnitude $M_{\mathrm{s}}$ for that time period was taken as the average of $M_{\mathrm{s}}$ from Uppsala (UPP) derived from long-period Benioff instruments and Kiruna (KIR) from Galitzin instruments, both calculated using the widely known formula (Karnik et al., 1962; Vanek et al., 1962):

$M_{\mathrm{S}}=\log (A / T)+1.66 \log \Delta^{\circ}+3.3$

where $T$ is the period in the range 10-30 s, $A$ the ground amplitude in microns and $\Delta$ the epicentral distance in degrees.

Since 1964, including the period covered in the present study when the ISC commenced determining body-wave magnitudes, $m_{\mathrm{b}}$, with continuously decreasing magnitude threshold, $M_{\mathrm{S}}$ is calculated according to the regression equation obtained by Makropoulos and Burton (1981):

$M_{\mathrm{S}}=1.37 m_{\mathrm{b}(\mathrm{ISC})}-1.74(\sigma= \pm 0.27, N=187)$

It should be noted that only events with $M_{\mathrm{s}} \geq 4.0$ corresponding to $m_{\mathrm{b}} \geq 4.2$ are included in the present catalogue. As Greece is a country that statistically experiences an earthquake of $M_{\mathrm{s}} \geq 6.1$ every year, the selected threshold of $M_{\mathrm{S}}=4.0$ is adequate for any seismic design purposes according to the Greek Building Code and to Eurocode 8.

\section{Moment magnitude $M_{\mathrm{w}}$}

The next goal of the present study was the determination of the moment magnitude scale, $M_{\mathrm{w}}$, for all events of the catalogue. $M_{\mathrm{w}}$ is considered by the worldwide seismological community to be the most reliable magnitude scale, since it is not saturated and is not dependent on the frequency window. Initially, the formulas obtained by Scordilis (2006):

$M_{\mathrm{W}}=0.67 M_{\mathrm{s}}+2.07$ for $3.0 \leq M_{\mathrm{s}} \leq 6.1$

$M_{\mathrm{w}}=0.99 M_{\mathrm{s}}+0.08$ for $6.2 \leq M_{\mathrm{s}} \leq 8.2$

were tested for the calculation of the moment magnitude. This procedure was not adopted, as for moderate events, $M_{\mathrm{W}}$ was found to be overestimated. For example, both $M_{\mathrm{s}}=4.0$ and 4.1 result to $M_{\mathrm{w}}=4.8$, while $M_{\mathrm{s}}=4.3$ or 4.4 result to $M_{\mathrm{w}}=5.0$.

Following the above and in order to obtain a homogeneous and reliable moment magnitude for the period 1900-2009, the available $M_{\mathrm{w}}$ for events of the catalogue which were directly calculated using regional or teleseismic modeling and moment tensor inversion by the below mentioned were traced:

a. the Department of Geophysics of the National and Kapodistrian University of Athens (NKUA, period: 2003-2007, magnitude range: 4.0-6.6, number of events: 148, http://www.geophysics.geol.uoa.gr, Agalos et al., 2007; Moshou et al., 2010), 


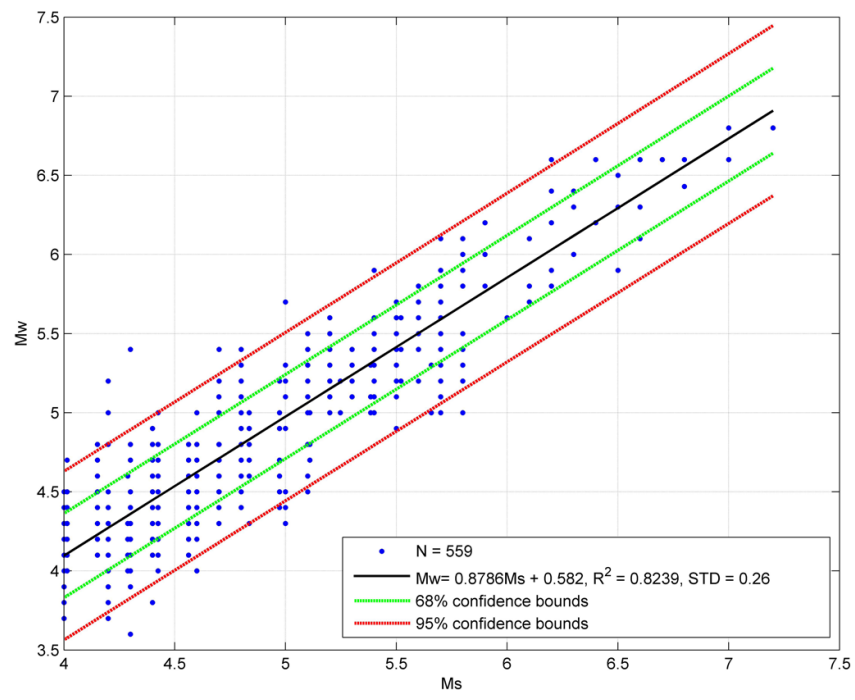

Fig. 1. Moment magnitudes $M_{\mathrm{W}}$ vs. surface wave magnitude $M_{\mathrm{S}}$ of the Greek catalogue.

b. the Global Centroid-Moment-Tensor (CMT) Project (period: 1976-2007, magnitude range: 4.6-6.8, number of events: 279 , http://www.globalcmt.org),

c. the Geodynamic Institute of the National Observatory of Athens (NOA, period: 2005-2007, magnitude range: 3.9-6.4, number of events: 75, http://bbnet.gein.noa.gr, Melis and Konstantinou, 2006) and

d. the catalogue of Konstantinou et al. (2010) that includes the database of the National Observatory of Athens (period: 2001-2006, magnitude range: 3.6-6.5, number of events: 306).

In cases that moment magnitude was available by more than one source, the magnitude calculated by NKUA, then by CMT and finally by NOA, was selected. Thus, 559 events/datapoints, i.e. events of the catalogue with directly calculated $M_{\mathrm{w}}$ were obtained.

Therefore, a relation between the surface wave magnitude $M_{\mathrm{S}}$ and the moment magnitude $M_{\mathrm{w}}$ was obtained (Fig. 1) using linear regression:

$M_{\mathrm{W}}=0.8786 M_{\mathrm{S}}+0.582\left(R^{2}=0.82, \sigma= \pm 0.26\right)$

where $R^{2}$ is goodness of fit and $\sigma$ is the standard deviation.

It should be stressed that the obtained equation yields rational results for all magnitudes including the moderate ones, i.e. $M_{\mathrm{S}}=4.0$ resulting to $M_{\mathrm{w}}=4.1$, while $M_{\mathrm{S}}=4.3$ to $M_{\mathrm{w}}=4.4$.

Using the above equation, $M_{\mathrm{w}}$ values were determined for all events of the current catalogue.
Table 1. Results of the completeness test for Greece (1900-2009).

\begin{tabular}{lrc}
\hline & $\begin{array}{r}\text { Time required for } \\
\text { stable recurrence } \\
\text { rate }(\mathrm{yr})\end{array}$ & $\begin{array}{c}\text { Period of } \\
\text { completely } \\
\text { reported events }\end{array}$ \\
\hline$M_{\mathrm{s}} \geq 4.0\left(M_{\mathrm{W}} \geq 4.1\right)$ & 5 & $1976-2009$ \\
$M_{\mathrm{S}} \geq 4.5\left(M_{\mathrm{W}} \geq 4.5\right)$ & 20 & $1950-2009$ \\
$M_{\mathrm{S}} \geq 5.0\left(M_{\mathrm{w}} \geq 5.0\right)$ & 25 & $1940-2009$ \\
$M_{\mathrm{S}} \geq 5.5\left(M_{\mathrm{W}} \geq 5.4\right)$ & 45 & $1911-2009$ \\
$M_{\mathrm{S}} \geq 6.0\left(M_{\mathrm{W}} \geq 5.9\right)$ & 60 & $1900-2009$ \\
\hline
\end{tabular}

\section{Completeness}

In order to assess the degree of completeness, that is to find the magnitude above which the catalogue can be considered as reasonably complete or alternatively, to assign time intervals in which a certain magnitude range is likely to be completely reported, the method introduced by Stepp (1971) was used. According to this method the occurrence rate $\lambda(M)$ is modeled as a point Poisson process in time:

$\lambda(M)=N(M) \mathrm{yr}^{-1}$

where $N$ is the number of events with magnitudes in the class $M$. For a period of $T$ years, the variance $\sigma_{\lambda}^{2}$ of $\lambda(M)$ is $\lambda / T$. For stationarity, $\sigma_{\lambda}$ should be parallel to $T^{-1 / 2}$ and discrepancies will imply that either the sub-interval $T$ is not long enough to give a good estimate of the mean $\lambda(M)$ or that these sub-intervals include periods in which reports are incomplete. A detailed description is provided in Makropoulos and Burton (1981).

The results are summarized in Table 1. It can be seen that events with surface wave magnitude above 4 are completely reported for the last $34 \mathrm{yr}$ (1976-2009). The earthquakes of half a magnitude unit larger are completely reported for the last $60 \mathrm{yr}$ of the catalogue and events with $M_{\mathrm{s}} \geq 5.0$ or $M_{\mathrm{s}} \geq 5.5$ after 1940 and 1911, respectively. It is worth noting that no earthquake with magnitude 6 or greater seems to have been omitted for the whole study period.

\section{Results - conclusions}

The new earthquake catalogue for Greece and adjacent areas presented covers the instrumental period 1900-2009. The area of investigation is limited, as in the previous versions of the catalogue (Makropoulos and Burton, 1981; Makropoulos et al., 1989), to latitudes $33^{\circ} \mathrm{N}$ to $42.5^{\circ} \mathrm{N}$ and longitudes $19^{\circ} \mathrm{E}$ to $29^{\circ} \mathrm{E}$ north of the $38^{\circ} \mathrm{N}$ parallel and to $30^{\circ} \mathrm{E}$ south of it, while the threshold magnitude is $M_{\mathrm{S}}=4.0$.

For the period 1986-2009, for which the catalogue was extended, all hypocenters of events with $m_{\mathrm{b}(\text { ISC) }} \geq 4.2$ were extracted from the bulletins of the ISC. The surface wave magnitudes $M_{\mathrm{S}}$ were calculated using the regression Eq. (2). 


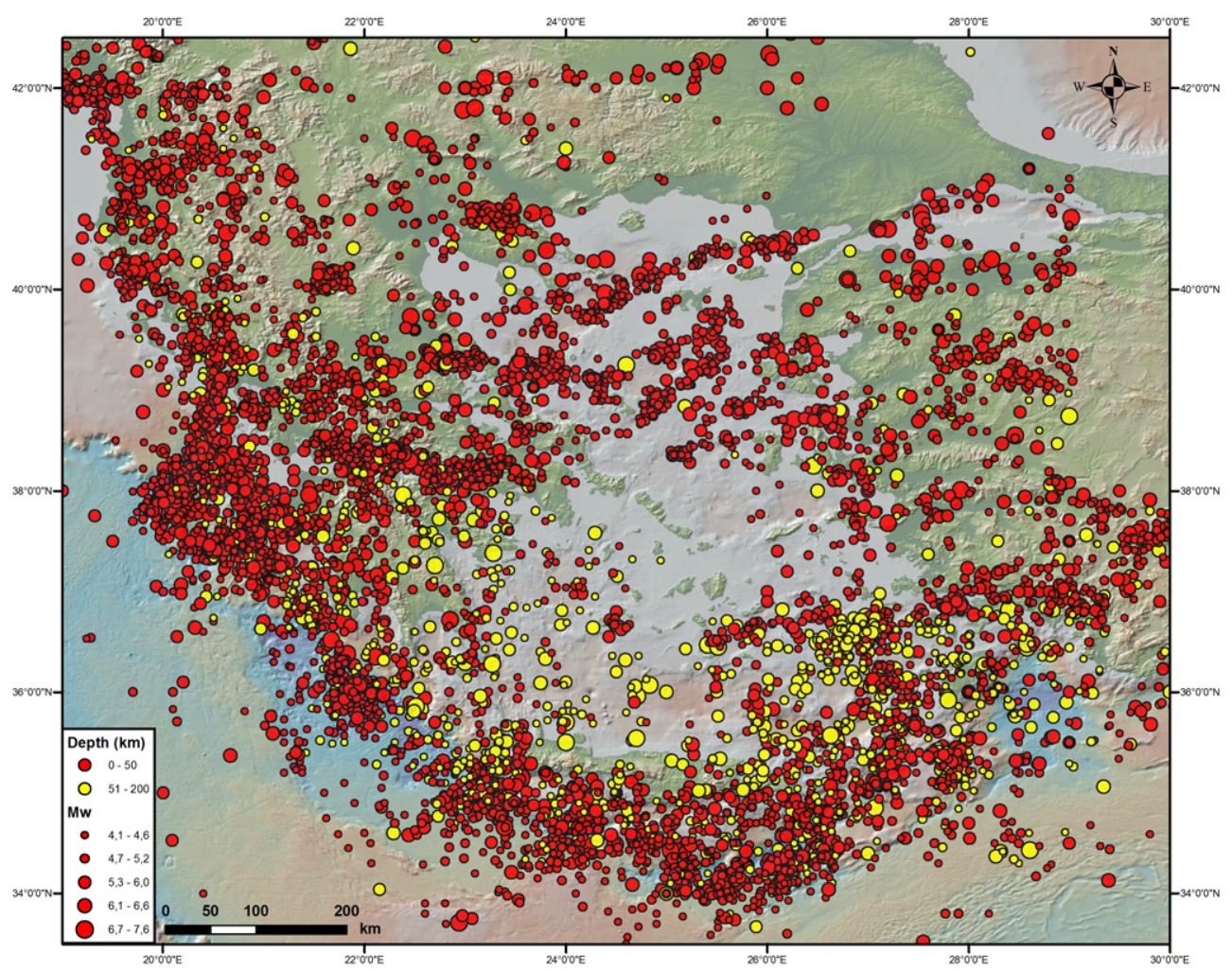

Fig. 2. Spatial distribution of the epicentres of both shallow and intermediate depth earthquakes in Greece and adjacent areas during the period 1900-2009.

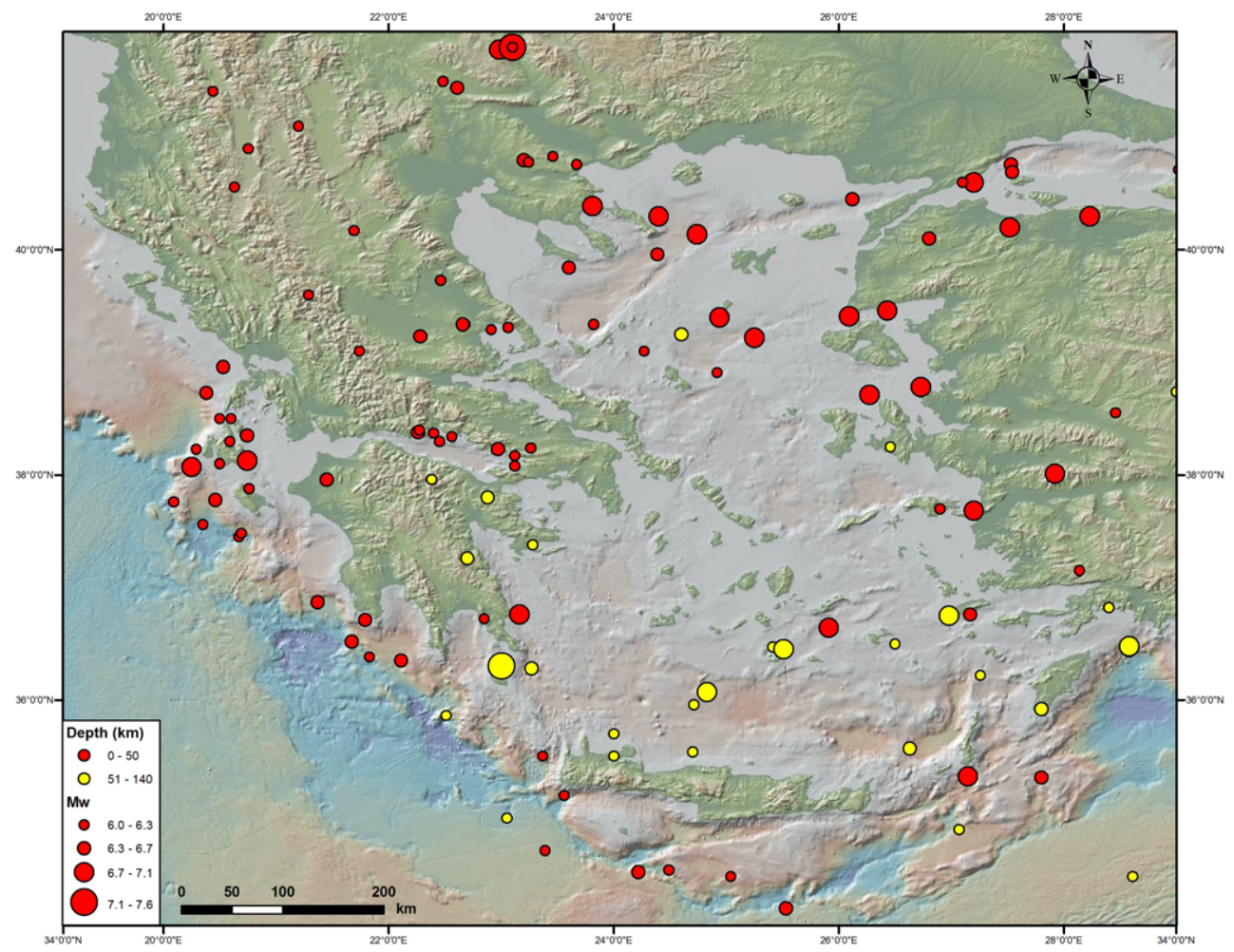

Fig. 3. Spatial distribution of the epicentres of events with $M_{\mathrm{W}} \geq 6.0$ in Greece and adjacent areas during the period 1900-2009. 
In the framework of the present study, the moment magnitude $M_{\mathrm{w}}$ was obtained for all the events since 1900 . This was achieved by applying the Eq. (5) between $M_{\mathrm{S}}$ and $M_{\mathrm{w}}$, which was derived by linear regression using 559 directly calculated moment magnitudes in the magnitude range $3.6 \leq M_{\mathrm{w}} \leq 6.8$.

The present version comprises 7352 events, for which the spatial distribution is shown in Fig. 2, whereas the previous version (Makropoulos et al., 1989) included 4310 events. The increase of the number of events since 1986 is mainly due to the growth of the number of seismic stations, including both local and regional networks. The 132 events of the final catalogue with $M_{\mathrm{w}} \geq 6.0$, a threshold which coincides with the most probable annual maximum for Greece, are presented in Fig. 3. In order to preserve the high degree of homogeneity and accuracy (Bath, 1983a, b) achieved in the previously published versions of the catalogue, the treatment of the data sets was identical.

It is obvious from both Figs. 2 and 3 that earthquake sources are spread throughout Greece, except certain Cyclades islands and Thrace. The majority of shallow earthquakes are included in a belt parallel to the Hellenic Arc, which extends north into Albania and south-east to the west coast of Turkey. Intermediate depth earthquakes are mainly located within the back-arc region. Significant concentrations of epicenters are observed in the Gulf of Corinth, as well as along the westward extension of the north Anatolian Fault into the Aegean (Makropoulos and Burton, 1984). In cases of aftershock sequences, such as the ones of Thessaloniki 1978, Volos 1980 and Alkyonides 1981, the events clustering can be easily observed. The addition of $24 \mathrm{yr}$ of seismicity (1986-2009) did not modify the conception on the general seismicity pattern of Greece. However, recent seismicity clusters associated with events, like KozaniGrevena 1995 and Athens 1999, were identified in regions lacking previous significant activity.

An electronic version of the catalogue is available online at the webpage of the Department of Geophysics, National and Kapodistrian University of Athens: http://www.geophysics. geol.uoa.gr/catalog/1900-2009_mkk.xls.

Within the process of catalogue updating and control, a number of additional earthquakes were identified from the UNESCO (Shebalin et al., 1974a, b) catalogue for the period 1900-1963. These events were not included in the previous versions of the catalogue, as they were not traced on the seismograms of Kiruna or Uppsala stations. However, 24 of them having $I_{\max } \geq 7$ (MM/MCS/MSK), could be taken into account for more elaborated seismic hazard assessment purposes. Therefore, and in order to avoid any contamination of the main catalogue as far as source homogeneity is concerned, it was decided to include them in a Supplement, which is also available at the link: http://www.geophysics. geol.uoa.gr/catalog/appendix_mkk.txt.
Supplementary material related to this article is available online at:

http://www.nat-hazards-earth-syst-sci.net/12/1425/2012/ nhess-12-1425-2012-supplement.zip.

Acknowledgements. We would like to thank N. Sakellariou, I. Misailidis and G. Sakkas for their contribution in the compilation of the present version of the catalogue.

Edited by: M. E. Contadakis

Reviewed by: A. Tselentis and another anonymous referee

\section{References}

Agalos, A., Papadimitriou, P., Voulgaris, N., and Makropoulos, K.: Source Parameters Estimation from Broadband Regional Seismograms for Earthquakes in the Aegean Region and the Gorda Plate, Bulletin of the Geological Society of Greece 2007 Proceedings of the 11th International Congress, Athens, 24-26 May 2007, 1032-1044, 2007.

Alsan, E., Tezucan, L., and Bath, M.: An earthquake catalogue for Turkey for the interval 1913-1970, Common Report No. 7-75 of Kandilli Observatory, Turkey and Seismic Institute, Uppsala, Sweden, 1975.

Bath, M.: Earthquake frequency and energy in Greece, Tectonophysics, 95, 233-252, 1983a.

Bath, M.: The seismology of Greece, Tectonophysics, 98, 165-208, 1983b.

Burton, P. W., Xu, Y., Qin, C., Tselentis, G.-A., and Sokos, E.: A catalogue of seismicity in Greece and the adjacent areas for the twentieth century, Tectonophysics, 390, 117-127, 2004.

Crampin, S. and Ucer, S. B.: The seismicity of the Marmara Sea region of Turkey, Geophys. J. R. Astr. Soc., 40, 269-288, 1975.

Douglas, A.: Joint Epicenter Determination, Nature, 215, 47-48, 1967.

Galanopoulos, A. G.: Katalog der Erdbeben in Griechenland für die Zeit von 1879 bis 1892, Annl. Geol. Pays Hell., 5, 114-229, 1953.

Galanopoulos, A. G.: A catalogue of shocks with $\mathrm{I}_{0} \geq \dot{\mathrm{VI}}$ or $M \geq 5$ for the years 1801-1958, 1960.

Herrin, E., Tucker, W., Taggart, D., Gordon, W., and Lodbell, J. L.: Estimation of source focus P travel times, Bull. Seism. Soc. Am., 58, 1273-1291, 1968.

International Seismological Centre (ISC): On-line Bulletin, available at: http://www.isc.ac.uk, Internatl. Seis. Cent., Thatcham, United Kingdom, 2010.

Kahle, H. and Mueller, S.: Structure and dynamics of the EurasianAfrican/Arabian plate boundary system: Objectives, tasks and resources of the WEGENER group, Journal of Geodynamics, 25, 303-325, 1998.

Kárnik, V.: Seismicity of the European Area, Part I, Academia, Praha, 1969.

Kárnik, V., Kondorskaya, N., Riznitchenko, J., Savarensky, E., Soloviev, S., Shebalin, N., Vanek, J., and Zatopek, A.: Standardisation of the earthquake magnitude scale, Studia Geoph. et Geod., 6, 41-47, 1962. 
Konstantinou, K. I., Melis, N. S., and Boukouras, K.: Routine Regional Moment Tensor Inversion for Earthquakes in the Greek Region: The National Observatory of Athens (NOA) Database (2001-2006), Seism. Res. Lett., 81, 750-760, doi:10.1785/gssrl.81.5.750, 2010.

Makropoulos, K. C.: The statistics of large earthquake magnitude and an evaluation of Greek seismicity, $\mathrm{PhD}$ Thesis, Edinburgh University, 198 pp., 1978.

Makropoulos, K. C. and Burton, P. W.: A catalogue of Seismicity in Greece and the Adjacent Areas, Geophys. J. R. Astr. Soc., 65, 741-762, and Microfiche GJ65/1, 1981.

Makropoulos, K. C. and Burton, P. W.: Greek Tectonics and Seismicity, Tectonophysics, 106, 275-304, 1984.

Makropoulos, K. C., Drakopoulos, J., and Latoussakis, J. B.: A revised and extended earthquake catalogue in Greece since 1900, Geophys. J. Int., 98, 391-394, 1989.

Melis, N. S. and Konstantinou, K. I.: Near real-time seismic monitoring in the Greek region: An example of the October 17, 2005 East Aegean Sea earthquake sequence, Seism. Res. Lett., 77, 364-370, 2006.

Moshou, A., Papadimitriou, P., and Makropoulos, K.: Moment tensor determination using a new waveform inversion technique, Bull. Geol. Soc. Greece, Proc. of the 12th International Congress, Patras, May 2010, XLIII, 4, 2104-2113, 2010.
Papazachos, B. C. and Comninakis, P. E.: A catalogue of earthquakes in Greece and the surrounding area for the period 19011980, Publ. Univ. of Thessaloniki, Geophys. Lab., 5, 1-146, 1982.

Papazachos, B. C., Comninakis, P. E., Scordilis, E. M., Karakaisis, G. F., and Papazachos, C. B.: A catalogue of earthquakes in the Mediterranean and surrounding area for the period 1901-Sep 2009, Publ. Geophys. Laboratory, University of Thessaloniki, 2009.

Schmidt, J.: Studien über Erdbeben, Leipzig, 1879.

Scordilis, E. M.: Empirical global relations converting $M_{\mathrm{S}}$ and $m_{\mathrm{b}}$ to moment magnitude, J. Seismol., 10, 225-236, 2006.

Shebalin, N. V., Kárnik, V., and Hadzievski, D.: Catalogue of Earthquakes. Part I, 1901-1970, UNDP/UNESCO Survey of the Seismicity of the Balkan Region, Skopje, 1974a.

Shebalin, N. V., Kárnik, V., and Hadzievski, D.: Atlas of Isoseismals, Part III, UNDP/UNESCO Survey of the Seismicity of the Balkan Region, Skopje, 1974b.

Stepp, J. C.: An investigation of earthquake risk in the Puget Sound area by use of the type I distribution of largest extremes, $\mathrm{PhD}$ thesis, Pennsylvania State University, 131 pp., 1971.

Vanek, J., Karnik, V., Zatopek, A., Kondorskaya, N., Riznitchenko, J., Savarensky, E. F., Soloviev, S. V., and Shebalin, N., V.: Standarization of magnitude scales, Bull. Acad. Sci. USSR. Geophys. Ser., 2, 108-111, 1962. 